\title{
DETECTION OF ANABOLIC STEROIDS BY RADIOIMMUNOASSAY
}

\author{
R. V. BROOKS, R. G. FIRTH and N. A. SUMNER
}

St. Thomas's Hospital Medical School, London, S.E.1

The synthetic anabolic steroids have structural features which distinguish them from the natural steroid hormones. It should therefore be possible to detect the taking of these substances by testing for their presence in either blood or urine. At present suitable techniques include gas chromatography, mass spectrometry and radioimmunoassay. For practical and psychological reasons urine tests are preferred although, as with the natural steroid hormones, only a small proportion of the anabolic steroid is excreted unchanged in the urine. A much larger proportion of the steroid usually undergoes minor chemical modification before being conjugated with glucuronic or sulphuric acids and is then excreted in the urine. It is this larger conjugated fraction which is usually used in the gas chromatography and mass spectrometry methods. Because of the great sensitivity of the radioimmunoassay technique we have so far used only the unconjugated steroid.

Principle of radioimmunoassay. Unlike the natural steroid hormones the protein hormones vary in structure from species to species. When a protein hormone from one species is injected into a different species antibodies may be produced. The antisera produced by this second species can be used as a reagent for measuring the hormone. Also needed for this assay system are a pure sample of the hormone to be measured (this as standard) and a sample of the hormone labelled with a radioactive isotope -125 | or ${ }^{131}$ | labelling of the tyrosine units in the protein is usually used.

If a dilution of the antiserum is taken so that the amount of antibody is limited and this is reacted with some of the radioactive hormone and a non radioactive hormone standard there will be competition between the labelled and unlabelled hormone. The hormone-antibody complex can be separated from the unreacted hormone by a variety of techniques and the distribution of radioactivity between the two fractions measured. Clearly the more of the non-radioactive hormone present the smaller will be the proportion of radioactivity bound.

If a graded series of standards is set up containing increasing amounts of unlabelled hormone with a fixed amount of radioactive hormone and antiserum, a standard curve can be drawn. As the amount of standard hormone increases, so the amount of radioactivity bound decreases. Unknown samples of hormone can then be assayed against this standard curve.

Steroid molecules are too small to be antigenic. How- ever, if a steroid molecule is firmly attached to a pure protein by covalent links and then injected into a foreign species (i.e. one foreign to the protein) antibodies will be produced, e.g. we could have testosterone linked to pure bovine serum albumin and then injected into a guinea pig.

The surprising thing is that some of the antibodies produced are specific against tive free steroid. We can therefore have a RIA for the steroid and use as radioactive indicator either the ${ }^{3} \mathrm{H}$-labelled steroid or a steroid-protein conjugate labelled with ${ }^{125} \mathrm{I}$.

Unfortunately, the preparation of antisera is still rather more art than science. However, one of the generalizations that has emerged is that the specificity of the antisera produced tends to be directed to those parts of the molecule remote from the point of attachment of the steroid to the protein. We thought that in case of the anabolic steroids we might simplify the problem by aiming for limited specificity. You will recall that all the orally active anabolic steroids have either a 17- $\alpha$-Methyl or a 17- $\alpha$-ethyl substituent. In this way they differ from all natural steroid hormones. By directing the specificity towards this end of the molecule (the $D$ ring) and away from the $A$ ring by attaching to the protein at this end it was hoped that just 2 antisera might be sufficient. An antiserum raised to norethandrolone-human serum albumin was hoped to cover the other $17 \alpha$-ethyl anabolic, ethyl estrenol also. One raised to $17 \alpha$-methyl testosterone was aimed to cover all the other $17 \alpha$-methyl steroids, e.g. Methandienone, Stanozolol and Oxymetholone. (Fig. 1).

After many attempts we obtained good antisera for both the $17 \alpha$-methyl and the $17 \alpha$-thyl-groups of steroids. The $17 \alpha$-methyl antiserum cross reacts with all 12 $17 \alpha$-methyl steroids we have tried including methandienone, stanozolol and oxymetholone giving parallel calibration curves. It does not cross react with the $17 \alpha$-ethyl anabolics, ethyl estrenol and norethandrolone but the cross reaction with the natural hormone was unacceptably high at $5 \%$. However we found that testosterone acetate did not cross react at all and this gave the clue to removing the interference by the natural androgen. If a drop of pyridine and a drop of acetic anhydride is added to the urine extract, all the testosterone present is converted to testosterone acetate but the $17 \alpha$-alkylated anabolic steroids remain unaffected, i.e. the acetate group becomes attached to the hydroxy group at $\mathrm{C}-17$ on testosterone but the presence 


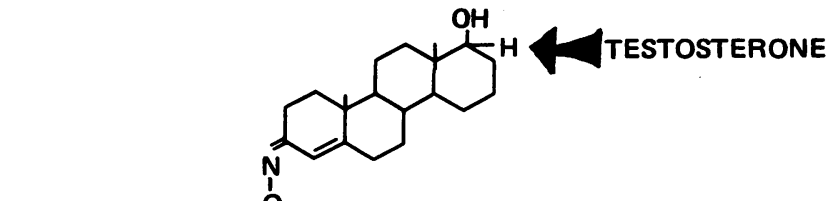

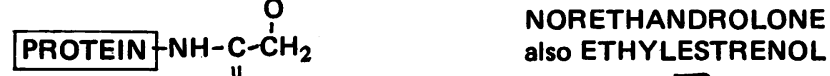
o

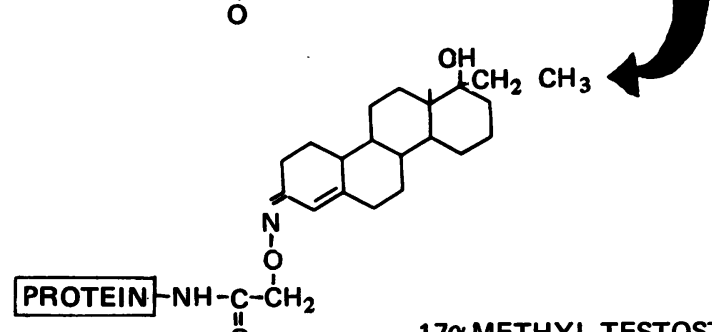

17 $\alpha$-METHYL-TESTOSTERONE also METHANDIENONE STANAZOLOL OZYMETHOLONE

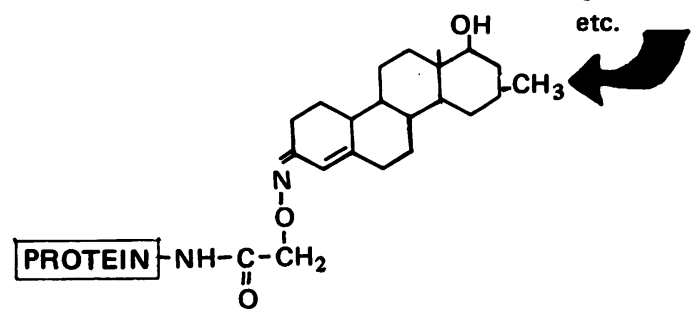

Fig. 1. Radioimmunoassay of Anabolic Steroids

of the bulky methyl or ethyl group on the anabolic steroid prevents this from happening. The method is shown in detail in the Appendix.

Characteristics of the Method. The method is relatively simple although it requires sophisticated radioactive counting equipment. The time for analysis, when carried out as a normal clinical procedure, is about 3 days. However, if unorthodox working schedules are adopted, a batch of samples received at the laboratory by $1800 \mathrm{~h}$ on day 1 could be ready by $1100 \mathrm{~h}$ on day 3 . Up to 30 samples could be run by one technician in a single batch giving a unit cost of about $£ 5$ per test. It is therefore less expensive than gas chromatography or mass spectrometry.

Anabolic steroids are unlike other drugs that have been used in athletics in that some of their effects can probably persist after the steroids have disappeared from the body, i.e. the muscles remain enlarged for some time after all trace of the anabolic steroid has been excreted. To be most effective, therefore, testing should ideally be randomised throughout the year and not confined to samples collected at athletic meetings. However, two factors suggest that this may not be necessary. Firstly it appears that it is necessary to take anabolic steroids for a prolonged period to have any effect. Secondly, because of its great sensitivity, the radioimmunoassay method is to a considerable and variable degree retrospective. These two factors, taken together, may make it impossible for an athlete to derive any competitive advantage from anabolic steroids if random tests are carried out at International meetings. The degree of retrospectivity afforded by the test may be increased by new antisera. The $17 \alpha$-methyl antiserum in current use is sensitive to $5 \mathrm{pg}$ of anabolic steroid - this is twice as sensitive as the one we had when the tests were announced in 1973. An even bigger increase in sensitivity might be obtained by hydrolysing the urine prior to extraction for radioimmunoassay. This would release for analysis the much larger quantities of anabolic steroid metabolites which are excreted in conjugated form but at the cost of some loss in simplicity and speed.

Future development. The screening test has been developed to detect all known orally active anabolic steroids. However, it seems likely that athletes will turn to anabolic steroids which are effective only if given by intramuscular injection such as Durabolin and Decadurabolin. These are both esters of 19-nortestosterone and we are at present preparing an antiserum against this steroid. If the antiserum is effective, this type of administration should be easier to detect since the depot effect of the injection will result in the drug being cleared from the body more slowly.

\section{Appendix}

\section{Method}

\section{Conjugate preparation}

The method adopted was essentially that of Erlanger et al., (1957). The steroid-3-(0-carboxymethyl) oxime derivatives were prepared as follows.

\author{
$50 \mathrm{mg}$ Steroid \\ $50 \mathrm{mg}$ (O-carboxymethyl) hydroxylamine \\ $1 \mathrm{ml}$ Methanol (dried by distillation over Calcium metal) \\ $50 \%$ saturated with $\mathrm{NaHCO}_{3}$.
}

The above mixture is shaken for $1 / 2 \mathrm{hr}$. at room temperature. Formation of the oxime is checked by thin layer chromatography (t.l.c.) of a small aliquot of the mixture on glass plates precoated with silica gel (Merck Kieselgel GF $_{254}$ ). Solvent system Benzene: Acetone: $\mathrm{MeOH}$ (I:I:l:by vol.). Steroids are located under UV $(254 \mathrm{~nm})$. Extraction and recovery of the steroid-oxime is then carried out according to Erlanger et al. 50 $\mathrm{mg}$ of the steroid-oxime is then used to form the mixed anhydride which is then linked to $200 \mathrm{mg}$ of human serum albumin. U.V. spectra of the steroid-HSA conjugate in this buffer $(2 \mathrm{mg} / \mathrm{ml})$ is used to indicate incorporation of steroid molecules into H.S.A. The lyophilised conjugates are stored at $4^{\circ} \mathrm{C}$.

Immunisation

2-2 $\frac{1}{2} \mathrm{~kg}$ New Zealand White Rabbits are used for immunisa- 
tion. $1 \mathrm{mg}$ of conjugate in $1 \mathrm{ml}$ of water is emulsified with $1 \mathrm{ml}$ of Freund's complete adjuvant. The emulsion is then injected subcutaneously into 10-15 dorsal sites. A booster dose is given after 6 weeks consisting of $1 \mathrm{mg}$ in $1 \mathrm{ml}$ of water and $1 \mathrm{ml}$ of Freund's incomplete adjuvant. This is injected subcutaneously into 3 dorsal sites. A sample of blood is obtained via the ear vein for titre and specificity studies. If an antisera of high titre and good specificity is obtained the particular animal is bled to death after Nembutal anaesthesia. The blood is collected and allowed to clot. After clot retraction the blood is centrifuged at $4^{\circ} \mathrm{C}$. The serum is removed and sodium azide (final concentration $0.1 \%$ ) is added as preservative. The serum is then stored at $4^{\circ} \mathrm{C}$ until required.

\section{Preparation of radioactive label}

\section{Tritium $(\boldsymbol{\beta} H)$}

Tritiated steroids of high specific activity are used commonly as labels in R.I.A. However, since no tritiated $17 \alpha$-methyl anabolic steroids are available commercially, 125 । labe!s have been used in this method.

\section{Radioiodine ( 125 )}

As direct iodination of most steroids is not possible then the radioiodine has to be incorporated into a secondary molecule attached to the steroid. Initially iodinated steroid-HSA conjugates were used as labels but were found unsuitable because they had a low affinity for the antisera and were only usable for about 2-3 weeks after preparation.

Steroid-125/-histamine labels were first described by Nars and Hunter (1973). Radioiodine is incorporated into histamine by the chloramine $T$ method. The steroid-oxime is then linked to the iodinated histamine using the mixed anhydride method.

The advantage of using 125 , labels is the simplicity of counting and absence of quenching. One disadvantage is the relatively short half life of 125 , (60 days) compared to 12.4 years of tritium. Nevertheless, steroid-125/ histamine labels are useable for up to 3-5 months.

The method used was that of Nars and Hunter (1973) and consists of three parts: mixed anhydride formation, iodination of histamine and conjugation of iodinated histamine to the mixed anhydride.

\section{(a) Mixed anhydride formation.}

To the steroid-oxime (e.g. $17 \alpha$-methyltestosterone-3-oxime, $2.4 \mathrm{mg})$ in dioxan $(50 \mu \mathrm{l})$ add tri-N-butylamine: dioxan (1:5, $10 \mu l)$ and mix. Then add isobutylchloroformate: dioxan $(1: 10,10 \mu \mathrm{l}) \mathrm{mix}$ and stand for $20 \mathrm{~min}$ with occasional mixing. Add dioxan $(3.45 \mathrm{ml})$ at $10^{\circ} \mathrm{C}$ and mix.

\section{(b) Iodination of Histamine.}

To the $\mathrm{Na}^{125}$, (1-2 $\mathrm{mCi}$ ) in $10-20 \mu \mathrm{NaOH}$ solution las supplied Radiochemical centre, Amersham) add Histamine

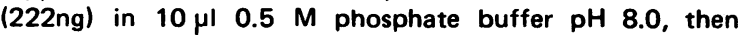
Chloramine-T (50 ug) in $10 \mu$ water. Mix vigorously 20-30 sec. Add sodium metabisulphite ( $300 \mu \mathrm{g})$ in $10 \mu$ l water.

\section{(c) Conjugation}

50 ul of the mixed anhydride solution from (a) added to the unseparated iodination mixture from (b) with mixing at $0^{\circ} \mathrm{C}$. Then add $10 \mu \mathrm{l} 0-1 \mathrm{~N} \mathrm{NaOH}$ and leave $1 \mathrm{hr}$. Again add
$10 \mu l 0.1 \mathrm{~N} \mathrm{NaOH}$ and leave $1 \mathrm{hr}$. Finally add $0.9 \mathrm{ml} 0.1 \mathrm{~N}$ HC1.

Extract with $1 \mathrm{ml}$ Toluene - (Tl-acid toluene). Separate TI from aqueous. The acid toluene layer $\mathrm{TI}$ contains the unconjugated iodinated histamine and is rejected. The aqueous layer is now made alkaline by the addition of $0.9 \mathrm{ml} 0.1 \mathrm{~N}$ $\mathrm{NaOH}$ and $1 \mathrm{ml}$ of $0.5 \mathrm{M} \mathrm{pH} 7.0$ buffer added. The aqueous solution is now extracted with $0.5 \mathrm{ml}$ Toluene (T2-neutral toluene) and the organic layer separated fron the aqueous. The neutral toluene extract (T2) contains the 125 /-labelled histamine-steroid conjugate, which is then purified on a thin layer chromatogram (Merck Kieselgel GF $_{254}$, solvent system Benzene: ethanol: acetic acid, 75:24:1 by voll. The position of the labelled conjugate ( $R_{F}$ about 0.47 ) can be located by overlaying the t.l.c. plate with Kodirex $x$-ray film for 5-10 $\mathrm{min}$. The film is developed and the region corresponding to the located label is scraped from the t.l.c. plate and eluted with $5 \mathrm{ml}$ of redistilled ethanol in which form it is stored. Before setting up an assay, a sufficient volume of this solution is taken to contain $10,000 \mathrm{cpm} /$ assay tube. This is evaporated and redissolved in the phosphate/albumin assay buffer (volume: $0.1 \mathrm{ml} /$ assay tube).

These labels are found to be very satisfactory because

1. Use of 125 | requires short counting times and no quench correction need be applied.

2. Approximately $50-60 \%$ of label found in zero tube (i.e. when only label and antisera are incubated).

\section{Sample preparation}

$0.5 \mathrm{ml}$ of serum, or urine, is extracted with $2.5 \mathrm{ml}$ of redistilled methylene dichloride in glass tubes $(100 \times 12 \mathrm{~mm})$ by vortex mixing for $1 / 2 \mathrm{~min}$. The upper aqueous layer was removed by suction and the organic layer is then washed.

$\times 1$ with $0.5 \mathrm{ml} 0.1 \mathrm{~N} \mathrm{NaOH}$

$\times 3$ with $0.5 \mathrm{ml} \mathrm{H}_{2} \mathrm{O}$ (until neutral)

Washes are removed by suction and discarded. The washed organic extract is then carefully poured into another clean tube ensuring that any remaining aqueous is left in the extraction tube. This usually happens because the aqueous tends to stick to the wall of the tube allowing the solvent to be poured off.

The organic extract is then taken to dryness in a warm water bath by blowing a stream of air onto the surface of the liquid. The tubes are then wiped to remove any excess moisture on the outside and dried in a vacum dessicator for at least $\mathbf{3 0} \mathrm{min}$ over $\mathrm{P}_{2} \mathrm{O}_{5}$. The contents of the dry tubes are then acetylated by the addition of 6 drops of pyridine and 3 drops of acetic anhydride and the tubes are sealed with parafilm. Acetylation is carried out overnight in the dark at room temperature.

1.2 $\mathrm{ml}$ of methanol are then added to the tubes and the solvent and excess reagents removed as previously described for drying down of organic extract.

$2.5 \mathrm{mls}$ of assay buffer are then added to the tubes to take up the extract. (This constitutes a dilution of 1 in 5 of the 'original serum or urine sample). 
Triplicate $0.1 \mathrm{ml}$ aliquots of the extract in assay buffer are used for each determination.

\section{Assay}

The method is based on the fact that antibodies can be coated onto plastic tubes. This enables simple and rapid separation of bound and free steroids. One then has only to count the plastic tube to evaluate the amount of bound radioactivity.

Plastic tubes (11/2" $\times 1 / 4^{\prime \prime} M$ and H Plastics (Romford) Ltd., Chesham Close, Romford, RM7 7NJ, Essex, England) are precooled in a bench top refrigerated bath (an ice/water bath is just as good) for about 2 hours. An aliquot of the antisera is then diluted according to titre requirements $11: 25000$ was used for the Rabbit anti $17 \alpha$ methyl testosterone-3HSA) in Carbonate Buffer pH 9.6 0.05M.

$0.3 \mathrm{ml}$ of the diluted antisera is dispensed into the pre-cooled plastic tubes using a Cornwall repeating syringe and any bubbles removed by sharply tapping the tube. Antibody controls consist of $0.3 \mathrm{ml}$ of Buffer only. The tubes are then placed in a polythene bag and kept at $4 \circ \mathrm{C}$ overnight.

It is important that all the procedures involving coating of the tubes should be carried out in the cold (e.g. an ice/water bath) to ensure evenness of coating and reproducible results. The contents of the tubes are then aspirated and the tubes washed with $0.3 \mathrm{ml}$ of assay buffer (Phosphate/Albumin buffer $\mathrm{pH}$ 7.3-7.4, $9.2 \mathrm{~g} \mathrm{Na}_{2} \mathrm{HPO}_{4} ; 2.34 \mathrm{~g} \mathrm{NaH}_{2} \mathrm{PO}_{4} .2 \mathrm{H}_{2} 0 ; 6.7 \mathrm{ml}$ of $30 \%$ solution of bovine serum albumin; $\mathrm{NaCl}, 12 \mathrm{~g}$ and water to 2 litres). The buffer wash is aspirated and $0.1 \mathrm{ml}$ of buffer alone, sample or standards in assay buffer are then added to the appropriate tube with a $100 \mu \mathrm{l}$ Hamilton syringe fitted with a Cheney adaptor.

After a $1-2$ hour delay $0.1 \mathrm{ml}$ of the label solution is added using a Hamilton repeating syringe $10.1 \mathrm{ml}$ containing approximately $10,000 \mathrm{cpm}$ of steroid-125/-histamine label in assay buffer). The contents of the tube are then mixed on a vortex mixer, placed in a plastic bag and kept at $4^{\circ}$ overnight.

The contents of the tube are then aspirated and the tubes

\section{Fig. 2. Flow diagram of the method}

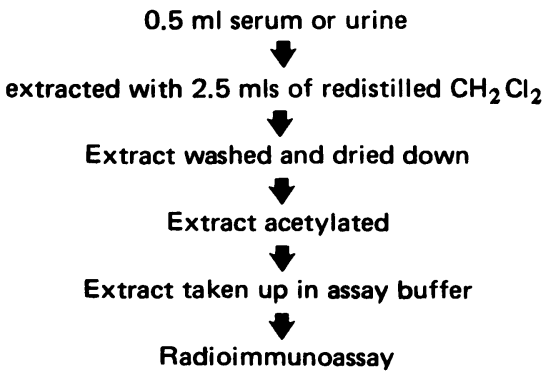

washed once with $0.3 \mathrm{ml}$ tap water. The wash is aspirated and the tubes counted in a gamma ray spectrometer.

The dilution of the serum or urine extract (1 in 5$)$ is performed because this considerably reduces the variation in control samples, i.e. zero value, and enables a value of $5 \mathrm{pg} /$ tube to be distinguished readily from zero.

Fig. 3.

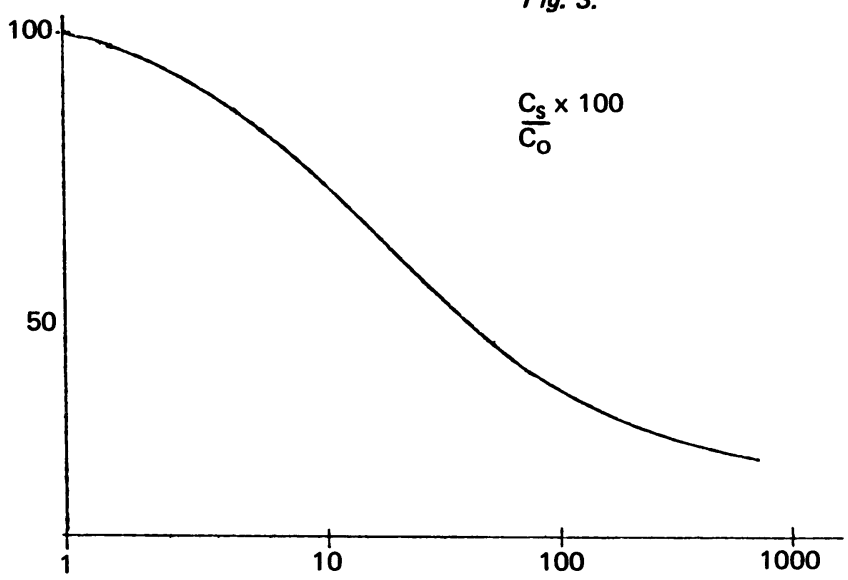

\section{Calculation}

The number of counts obtained from standard and sample tubes are related, on a percentage basis, to the zero tube (i.e. tube containing antibody and label only)

$$
\begin{array}{ll}
\frac{\mathrm{C}_{\mathrm{s}} \times 100}{\mathrm{C}_{\mathrm{O}}} & \mathrm{C}_{\mathrm{s}}=\begin{array}{l}
\text { cts } / \mathrm{min} \text { sample or } \\
\text { standard tube } \\
\text { cts } / \mathrm{min} \text { in zero } \\
\text { tube }
\end{array} \\
\mathrm{C}_{\mathrm{O}}=
\end{array}
$$

The $\vec{C}_{\mathrm{C}_{\mathrm{o}}}$ values for standard tubes are plotted against the amount of standard (pg/tube) on log-linear graph paper. Amounts in unknown samples are then read from this standard curve using the $\mathrm{C}_{\mathrm{s}}$ value in each case. (Figure 3 ).

$$
\mathrm{C}_{\mathrm{o}}
$$

For the assay of the $17 \alpha$ methyl anabolic steroids, the steroid used as standard is Methandienone ( $5 \mathrm{pg}-1000 \mathrm{pg} /$ tube). Therefore all values obtained from unknown samples are in "equivalents" of Methandienone.

A similar antiserum has been prepared for detecting $17 \alpha$-ethyl anabolic steroids.

This research was supported by a Grant from the English Sports Council.

\section{REFERENCES}

Erlanger, B. F., Borek, F., Beiser, S. M. and Lieberman, S. (1957) J.Biol.Chem., 228, 713-727.

Nars, P. W. and Hunter, W. M. (1973) J.Endocrin., 57 xlvii. 